\title{
DYNAMIC SIMULATION OF URBAN GREEN SPACE EVOLUTION BASED ON CA-MARKOV MODEL-A CASE STUDY OF HEXI NEW TOWN OF NANJING CITY, CHINA
}

\author{
SHEN, S. ${ }^{1 *}-$ CHEN, L. ${ }^{1}-$ FAN, C. ${ }^{2}-$ GAO, Y. ${ }^{2}$ \\ ${ }^{1}$ College of Landscape Architecture, Nanjing Forestry University, 210037 Nanjing, China \\ ${ }^{2}$ School of Architecture, Tsinghua University, 100084 Beijing, China \\ *Corresponding author \\ e-mail: shensg@njfu.edu.cn
}

(Received $8^{\text {th }}$ Mar 2019; accepted 21 ${ }^{\text {st }}$ May 2019)

\begin{abstract}
Based on the SPOT-5 images in 2004 and 2010 and SPOT-6 images in 2016 on the northern region of Hexi new town of Nanjing, the urban green space pattern of 2022 was predicted using the CA-Markov model. On this basis, four landscape indexes were used to analyze the evolution of green landscape pattern in the study area from 2004 to 2022. The results showed that the spatial accuracy of urban green space simulated by CA-Markov model was as high as $87.23 \%$, and the Kappa index was 0.8533 , which means high reliability. It is predicted that the scale of urban green space in the northern region of Hexi new town will continue to increase in 2016-2022, accounting for $17.28 \%$, and the patch area of the dominant green space will keep increasing. The number of green patches NP and complexity LSI show a downward trend, the green landscape begins to become orderly, the fragmentation is lessening, the green space network system is gradually formed, and the spatial layout of urban green space tends to be reasonable. The simulation results can provide decision-making basis for the dynamic control of urban green space of Hexi new town of Nanjing.
\end{abstract}

Keywords: the spatial accuracy of urban, Kappa index, the number of green patches, landscape index, the remote sensing image data

\section{Introduction}

Since the beginning of the 21 st century, with the advancement of global urbanization, China has been in the stage of urban space expansion driven by rapid urbanization. However, with the extensive and inefficient urbanization of land, the urban natural ecosystem is degrading, which further restricts the sustainable development of cites (Weber and Puissant, 2003; Daniel et al., 2018). Therefore, the land use and land cover change research has become a frontier and hot topic of global change research (Mooney et al., 2013; Ismail et al., 2019), and its importance is increasingly prominent in the study of global environmental change and sustainable development (Blumstein and Thompson, 2015; Mahmood et al., 2018). In urban planning, strengthening the control of green space layout can optimize the living environment and reduce the impact of urban development on the natural ecosystem. With the continuous development of the construction of the green space system, the intervention of its layout is a dynamic approach process, so the dynamic simulation method can effectively guide the planning of urban green space layout.

In recent years, the cellular automata model (CA) and the Markov model (Markov) are important predictive models in the field of land use dynamic simulation. The cellular automata, as a discrete grid dynamics model, has strong spatial computing ability and spatiotemporal coupling characteristics, which can effectively simulate complex spatiotemporal change processes (White and Engelen, 1993; Al-shalabi et al., 2013; Anan, 
2019). The Markov model was a prediction method created by A. Markov in 1940s, and it is also called Markov chain. The Markov chain is an analytical tool that can predict the future trends of variables (Paul et al., 2016). The Markov model was used by Hulst to solve the problem of vegetation ecological prediction (Hulst, 1979), and was also used by Balzter and Pastor to analyze vegetation changes (Balzter, 2000; Pastor et al., 2005; Xu, 2018).

At present, cellular automata model and Markov model have been widely used in land use change prediction. Markov model has great advantages in studying time evolution, but it is weak in spatial computing ability, while CA model has strong spatial computing ability (Liu and Chen, 2002). Therefore, the CA-Markov model, which combines the two methods, can simulate the land use change from both quantitative and spatial aspects (Halmy et al., 2015). It is more and more widely used (Weng, 2002; Ye, 2007), and has achieved better prediction results (Guan et al., 2011; Moghadam and Helbich, 2013; Anputhes et al., 2016). In addition, the CA-Markov model is mainly used to study largescale land use change, and there are a few dynamic simulation studies on open space or green infrastructure in foreign countries (Mitsova et al., 2016; Joseph et al., 2019). However, there are few dynamic simulation studies on urban green space expansion.

Compared with the simulation of dynamic change of construction land, the simulation of dynamic change of green space has two characteristics: (1) The green space has its own spreading process, because with the green plant growth, it will increase the vegetation coverage. (2) Another characteristic of green space expansion is that it is obviously influenced by human activities, for example, both sides of the new road and the waterfront space are highly adaptable to the green space layout. In this paper, CA-Markov model is applied to green space simulation, because the model can simulate the suitable green space spread phenomenon, this is an attempt and breakthrough for the study of green space (Lin, 2018a; Sarker et al., 2019). Using this method to study the law of spatial expansion of green space in the process of urbanization is not only helpful to forecast the law of green space development, but also to provide targeted optimization measures for urban green space layout. However, this study is particularly important for the control and optimization of green space layout in China's rapidly urbanized areas (Pascual-Córdova, 2018).

This paper takes the northern region of Hexi of Nanjing as the research area, takes the SPOT images of 2004, 2010 and 2016 as the land use information source, using CAMarkov model to construct the conversion rules of urban green space micro-land cells in the cellular automaton model and then use logistic regression model to construct a comprehensive evaluation model of urban green space expansion (Asgari, 2018). In this way, the spatial change of urban green space in the study area in 2022 is predicted and the landscape indexes is used to analyze the evolution characteristics of the overall green space landscape pattern in the study area from 2004 to 2022. The results can provide reference for the dynamic regulation of green space expansion in fast urbanized areas (Liu, 2018; Bind et al., 2018). At the same time, it also explores the scientific way of urban green space planning and construction, and explores new methods for the layout of urban green space.

\section{Research data and methods}

\section{Overview of the study area}

Nanjing Hexi new town is located in the southwest of Nanjing main city zone. According to the temporal evaluation, it is divided into three regions: the north, the middle 
and the south. The study area is the northern region of Hexi new town of Nanjing (Fig. 1), which is located on the west side of Nanjing main city zone, with Yangtze River in the west, external Qinhuai River in the east, Sancha River in the north, and Yingtian Avenue in the south, with a total area of $27.74 \mathrm{~km}^{2}$. The study area and its surrounding areas have rich natural and cultural landscapes such as Qingliang Mountain park, Stone park, Mochou lake park, Gulin park and Peach garden scenic belt and so on.

In recent years, Hexi new town of Nanjing has successfully hosted a series of major international and domestic events, such as the 10th National Games of China, China EU summit, Asian Youth Games, the Summer Youth Olympic Games, Nanjing International Marathon and World Speed Roller Skating Championships. At present, Hexi new town has become a city center with great potential for development, beautiful living environment and first-class functional quality in Nanjing.

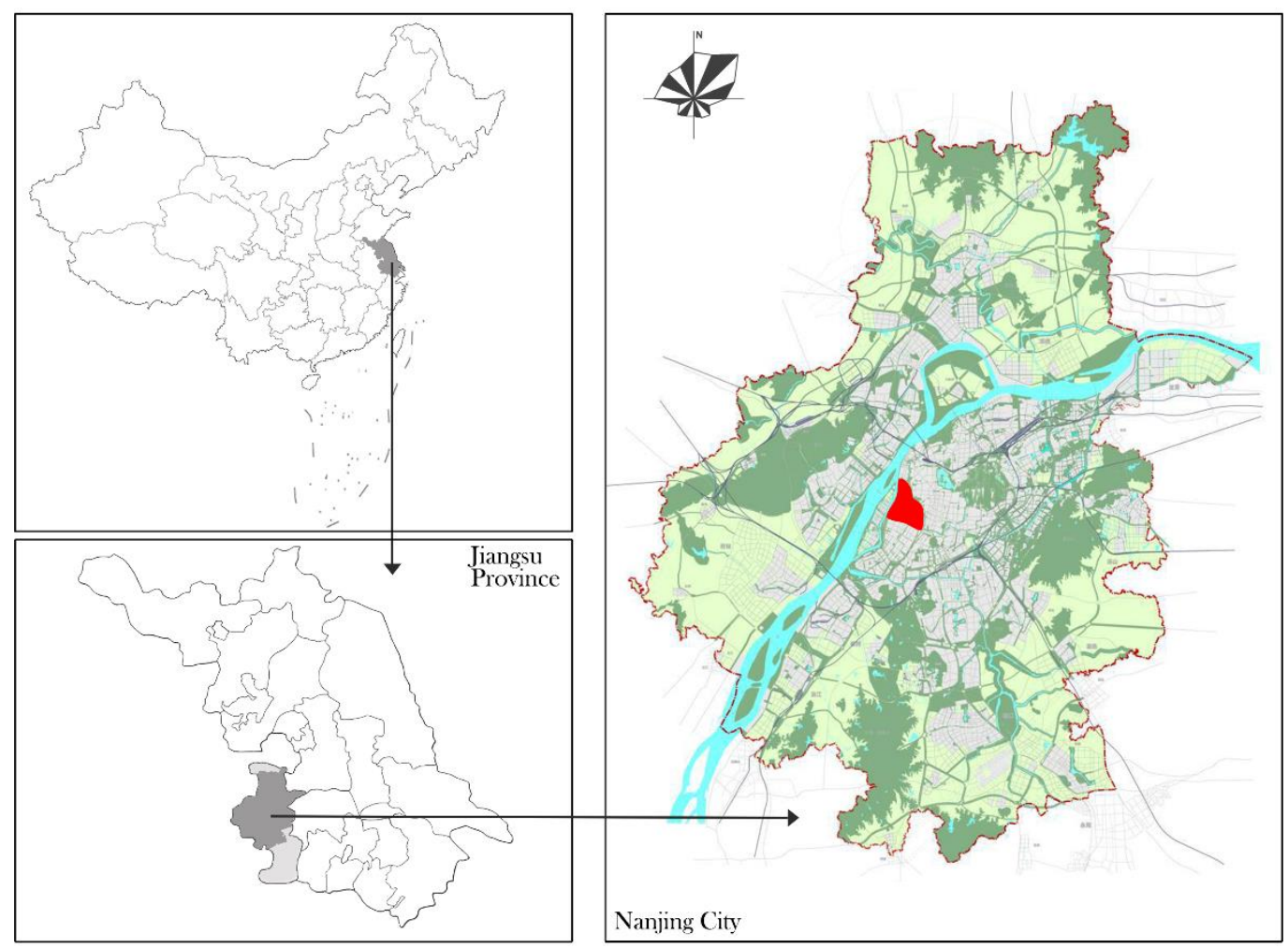

Figure 1. Study area

\section{Research data and preprocessing}

The remote sensing data used was three SPOT images covering the study area, including two SPOT-5 images (the acquisition time is June 2004 and June 2010, and spatial resolution is $2 \mathrm{~m}$ ), and one SPOT-6 image (the acquisition time is July 2016, and spatial resolution is $2 \mathrm{~m}$ ). Based on 1:25,000 topographic map, Gaussian Kriging projection (Xi' an 80 coordinate system, and central meridian $120^{\circ} \mathrm{E}$ ) was selected, and geometric accurate correction was carried out for SPOT images by two polynomial correction methods (the root mean square error is within 0.5 pixels). According to the first class classification standard in "LUCC (Land-Use and Land-Cover Change) Classification System" of the Chinese Academy of Sciences and "Technical 
Regulations for Land Use Investigation" in China, combined with the characteristics of the study area, the land use types of the study area were divided into five categories: water area, urban green space, urban road land, urban construction land, and open land (unused land). Based on the field survey data and the existing sample database, the remote sensing interpretation marks in the study area were established (Lin, 2018b; Naidu et al., 2018). The three images were supervised and classified by Maximum Likelihood (ML) in Easy Feature software and ARCGIS software, and the classification results were manually revised. Using field survey data, Google Earth image and Ovi interactive map, 100 points were randomly selected to evaluate the classification map. The overall accuracy of the image classification maps in 2004, 2010 and 2016 was 95\%, $96 \%$ and $97 \%$ respectively, which met the requirements of remote sensing interpretation accuracy. In ARCgis, the spatial distribution map of land use in the study area in 2004, 2010 and 2016 was formed.

\section{CA-Markov prediction model construction}

The CA-Markov model has both the predictive ability of Markov model and the advantage of cellular automata model in simulating the spatial changes of complex systems (Kamusoko et al., 2009). With the support of IDRISI software, the data probability transformation matrix in the study area is added to the cellular automata model. In the model, the transfer area and probability of each land use type were generated by Markov chain, and the image set of land use transfer suitability was created by logistic regression model. Finally, the future land use situation was simulated by CA cellular automata combined with transfer probability and transfer suitability atlas (Hu et al., 2013) (Fig. 2).

It should be pointed out that according to the principle of urban planning, the water and construction land cannot be converted between each other in study area. In addition, the time interval between remote sensing images is equal to 6 years, so each period of the change is iterated the same 6 times.

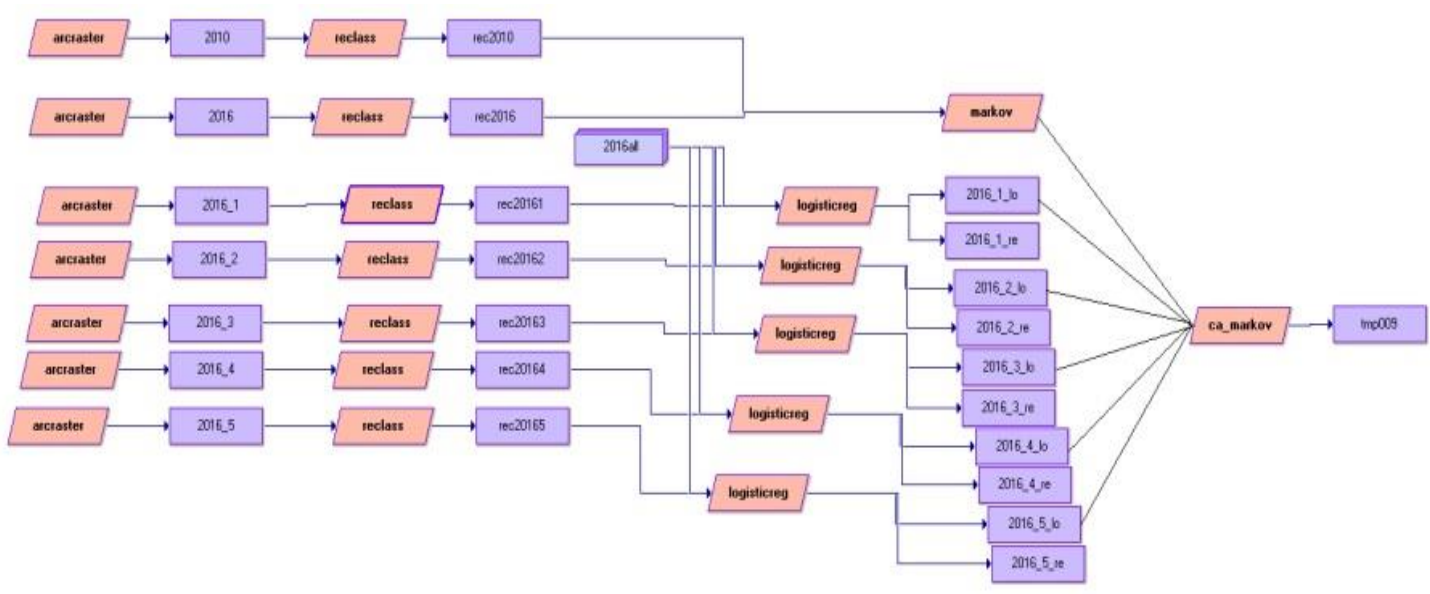

Figure 2. The flow chart of urban green space simulated dynamically by CA-Markov model

In this study, the dynamic simulation prediction of urban green space was realized based on the CA-Markov model. It should be carried out on the premise of ensuring the accuracy of the model, and the experimental periods were 2004, 2010 and 2016, with a 
time interval of 6 years. The prediction process was achieved through 2 steps. The first was the data accuracy test (Zuo et al., 2014) and spatial data test (Han et al., 2016). That was to say, the green space data and distribution in 2016 were predicted by the images from 2004 to 2010, and compared with the measured green space data in 2016, so as to test the feasibility and accuracy of this method. If the accuracy met the requirements, the second part was studied, that was the data and distribution of green space in 2022 were predicted through the 2010-2016 image data (Jiménez et al., 2016).

The specific steps were as follows: (1) According to the land use classification results of remote sensing images in the study area in 2004 and 2010, the transfer area matrix and transfer probability matrix of land use in 2004-2010 were obtained by Markov model. (2) The land change suitability image in 2004-2010 was made by using Logistic regression model. (3) Using CA-Markov model, the land use distribution map of 2010 was superimposed on the road network of 2016. On this basis, the land use transfer probability matrix and transfer suitability image set from 2004 to 2010 were used to predict the green land data and its distribution in 2016 (Huang, 2019). The proximity filter was set to $5 \times 5$. (4) In order to test the reliability of simulation results, the accuracy of the CA-Markov model should be verified. The land use classification map in 2010 was used as the initial image to predict the distribution of urban green space in 2016, and the predicted value in 2016 was compared with the actual value. In this paper, area accuracy (Eq. 1) and spatial accuracy (Eq. 2) are used to compare their consistency. In Equation 1, $\mathrm{m}_{\mathrm{iy}}$ and $\mathrm{m}_{\mathrm{ix}}$ are respectively the simulated area and the actual area of the $\mathrm{i}$ land, the higher of the E1 numerical value, the better the consistency between the simulated area and the actual area. In Equation 2, c $c_{i y}$ is the grid number of $i$ land in the land use simulation map, and $c_{i x}$ is the grid number of I class land in the land use actual map at the same location as $\mathrm{c}_{\mathrm{iy}}$. The same meaning, the higher of the E2 numerical value, the higher the spatial precision. In this study, it was feasible that E2 was set to $85 \%$. (5) According to the above (1)-(4) steps, the land use distribution map of 2016 was taken as the initial image, and the land use classification results of 2010 and 2016 remote sensing images in the study area were used to generate transfer probability matrix and land change suitability image set to predict the spatial distribution of green space in the study area in 2022.

$$
\begin{gathered}
E 1=\left\{1-\frac{\left|\mathrm{m}_{\mathrm{iy}}-m_{i y}\right|}{m_{i x}}\right\} \times 100 \% \\
E 2=\frac{\mathrm{c}_{i y}}{c_{\mathrm{ix}}} \times 100 \%
\end{gathered}
$$

\section{Urban green space landscape index acquisition}

Landscape index is used to quantitatively analyze the characteristics of landscape pattern (Riitters et al., 1995). In the landscape index analysis, four indexes of number of patches (NP), landscape shape index (LSI), the proportion of the largest patch to the landscape area (LPI) and Shannon diversity index (SHDI) were selected as the characteristic indexes reflecting landscape pattern (Zhang et al., 2014; Wu et al., 2016) (Table 1). The vector land use map was transformed into raster map by ArcGIS, and the 
vector diagram was transformed into Arc Grid format data with a size of $10 \mathrm{~m} \times 10 \mathrm{~m}$, and the above landscape indexes were calculated by Fragstats 4.2 software.

Table 1. Main landscape index and its ecological significance

\begin{tabular}{|c|c|c|c|c|}
\hline Index type & Index name & $\begin{array}{c}\text { English } \\
\text { abbreviation }\end{array}$ & $\begin{array}{c}\text { Application } \\
\text { scale }\end{array}$ & Ecological significance \\
\hline $\begin{array}{l}\text { Density and } \\
\text { diversity } \\
\text { index }\end{array}$ & $\begin{array}{l}\text { Number of } \\
\text { plaques }\end{array}$ & NP & Type/landscape & $\begin{array}{l}\text { It reflects the total number of patches } \\
\text { reflecting the patch type in the landscape, } \\
\text { which is positively correlated with the } \\
\text { degree of fragmentation of the landscape. } \\
\text { Generally, the larger the NP, the higher } \\
\text { the degree of fragmentation, the smaller } \\
\text { the NP, and the lower the broken degree }\end{array}$ \\
\hline Shape index & $\begin{array}{l}\text { Landscape } \\
\text { shape index }\end{array}$ & LSI & Type/landscape & $\begin{array}{l}\text { It reflects the shape complexity of the } \\
\text { overall landscape. The closer the LSI to } 1 \text {, } \\
\text { the simpler the overall landscape. The } \\
\text { larger the LSI is, the more complex it is }\end{array}$ \\
\hline Area index & $\begin{array}{l}\text { The proportion } \\
\text { of the largest } \\
\text { patch to the } \\
\text { landscape area }\end{array}$ & LPI & Type/landscape & $\begin{array}{l}\text { It reflects the degree of plaque } \\
\text { concentration and the dominant type of } \\
\text { landscape }\end{array}$ \\
\hline $\begin{array}{l}\text { Diversity } \\
\text { standard }\end{array}$ & $\begin{array}{c}\text { Shannon } \\
\text { diversity index }\end{array}$ & SHDI & Landscape & $\begin{array}{l}\text { It reflects the change of the quantity and } \\
\text { proportion of landscape components. In } \\
\text { the landscape composed of multiple } \\
\text { components, when the proportion of each } \\
\text { component is equal, the diversity index is } \\
\text { the highest }\end{array}$ \\
\hline
\end{tabular}

\section{Results and analysis}

\section{Change of land use structure in the study region in 2004-2016}

Based on the classification results of ARCGIS, all kinds of land use scale is shown in Table 2, and the mutual transformation of each land use type is complicated (Fig. 3). It can be seen that in 2004-2016: (1) The scale of construction land has been decreasing. This is mainly because in the process of urban construction, road and green space have been increasing, reducing the projection area of construction land. (2) The scale of roads increases first and then decreases because a large number of new roads have been added between 2004 and 2010, but the road green space has not been improved during this period. Between 2010 and 2016, the road green space has been gradually improved. With the increase of road green coverage, the roads are covered with greenery. (3) The scale of urban green space has increased rapidly. From 2004 to 2016, the scale of green space has been expanding and a green network system along the river and road has been formed. (4) During this period, the scale of open land (unused land) declined, mainly because a lot of wasteland was changed to construction land. (5) The size of water area changes little, indicating that the water system is well preserved.

\section{CA-Markov model constructed for prediction test}

Based on the CA-Markov urban green space prediction model constructed in Figure 2, the distribution and scale of green space and all kinds of land in 2016 were 
predicted by using data from 2004 to 2010 (Wang, 2019). The results are shown in Figure 4 and Table 2 . The predicted results were only 5\% less than the measured data in 2016 , the data precision $E$ of simulated green space was $87.23 \%$, and the spatial precision kappa coefficient was 0.8533 , indicating that it was feasible to use CAMarkov model to predict the dynamic change of green space (Fig. 4). Therefore, it was reliable to use this method to predict the size and layout of urban green space in 2022 by using the actual measurement of urban green space in 2010 and 2016.

Table 2. Statistics of all kinds of land use scale (unit: $\mathrm{km}^{2}$ )

\begin{tabular}{c|c|c|c|c|c|c}
\hline & $\begin{array}{c}\text { Land used } \\
\text { for building }\end{array}$ & Road & Green space & $\begin{array}{c}\text { River } \\
\text { system }\end{array}$ & Open space & Total \\
\hline $\begin{array}{c}\text { 2004 } \\
\text { actual measurement } \\
2010\end{array}$ & 19.32 & 2.81 & 1.52 & 1.79 & 2.31 & 27.74 \\
$\begin{array}{c}\text { actual measurement } \\
\text { 2016 }\end{array}$ & 18.09 & 3.81 & 2.65 & 1.72 & 1.48 & 27.74 \\
$\begin{array}{c}\text { actual measurement } \\
\text { 2016 }\end{array}$ & 17.73 & 3.55 & 4.20 & 1.73 & 0.54 & 27.74 \\
$\begin{array}{c}\text { premeasurement } \\
\text { 2022 }\end{array}$ & 17.66 & 3.91 & 3.97 & 1.70 & 0.50 & 27.74 \\
premeasurement & 17.28 & 3.48 & 4.79 & 1.73 & 0.46 & 27.74 \\
\hline
\end{tabular}

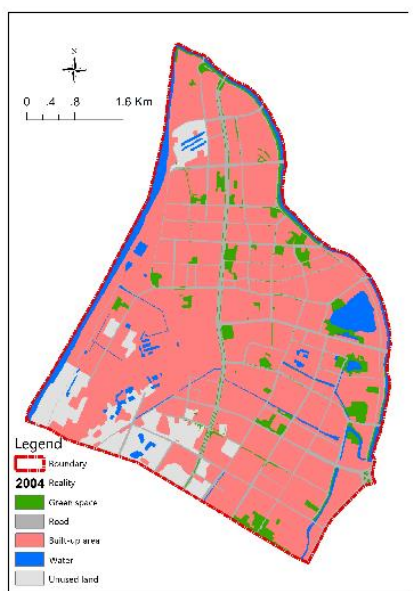

(a) 2004

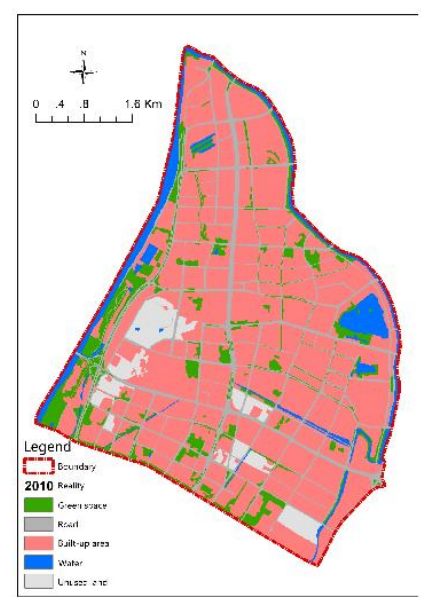

(b) 2010

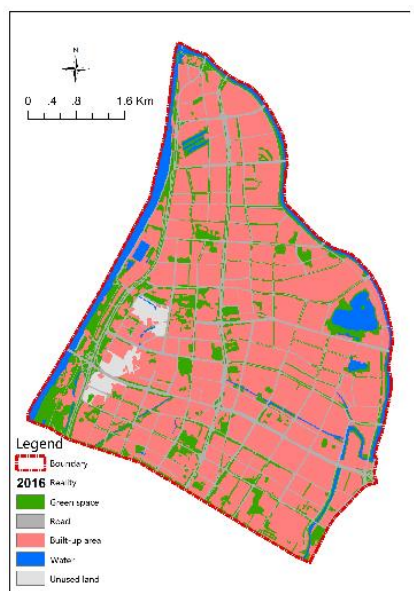

(c) 2016

Figure 3. Results of remote sensing image classification in the study area

\section{Prediction of urban green space change trend in 2022}

According to the land use change prediction of CA-Markov model (Table 2 and Fig. 5), in 2010-2016, on the whole, the change range of all kinds of land was smaller than the previous 12 years from 2004 to 2016. The urban green space will continue to improve in 2016-2022, and the scale will continue to increase. According to the forecast, the greening level of the riverside park of the Yangtze River and key roads will be higher than 2016, the width of green bandwidth will be further improved, the overall scale will be increased from $4.20 \mathrm{~km}^{2}$ in 2016 to $4.79 \mathrm{~km}^{2}$, but the improvement of 


$$
-8576-
$$

green space network will make the construction land and road (projected area) scale of the study area continue to decline, and the overall scale of both will be reduced by about $0.59 \mathrm{~km}^{2}$ (Yanyan et al., 2019).

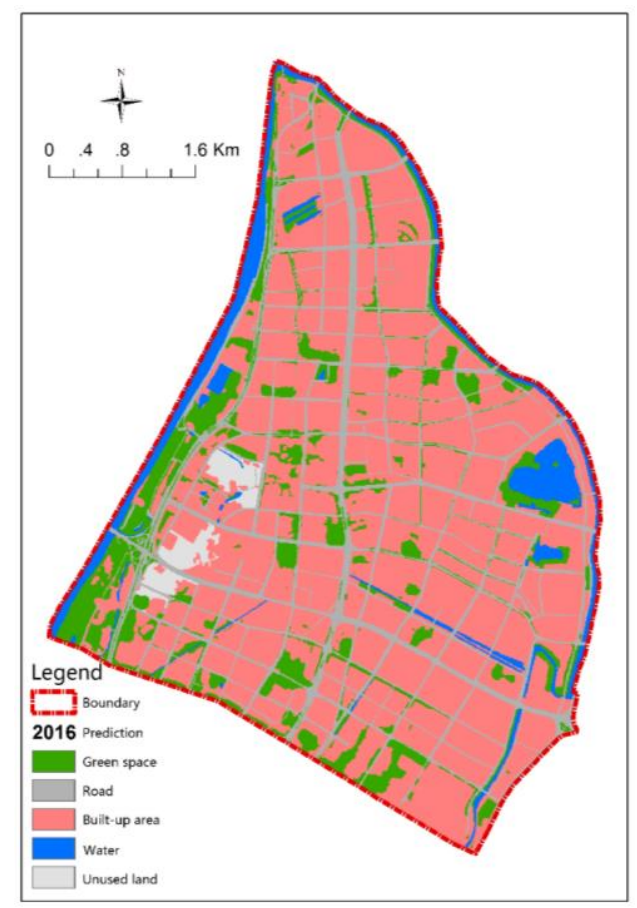

Figure 4. Prediction of green space distribution in 2016 based on remote sensing image data in 2004 and 2010

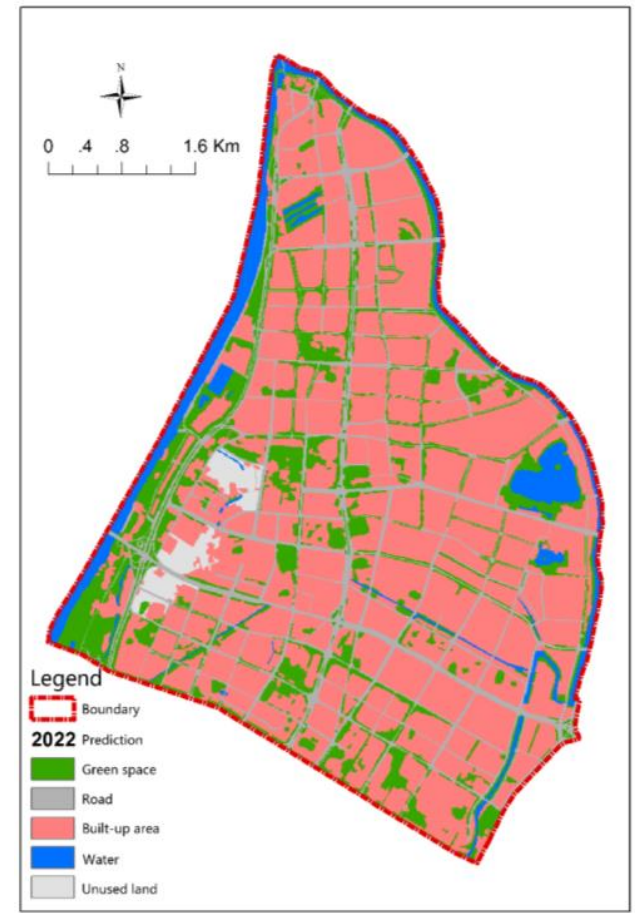

Figure 5. Prediction of green space distribution in 2022 based on remote sensing image data in 2004 and 2010 


\section{Green space landscape pattern analysis in 2004-2022}

Based on the measured land use distribution maps of 2004, 2010 and 2016 and the predicted land use distribution maps of 2022, 16 landscape indexes of four periods were calculated (Table 3). From Table 3 it can be seen that the number of patches of green space NP and the complexity LSI are on the rise, which indicates that the fragmentation and disorder degree of green space landscape in the study area became more and more serious between 2004 and 2016, and the mutual relationship between green space and all kinds of land became complex, and the degree of mosaic increased (Yu, 2019). From 2016 to 2022, the number of patches NP and complexity LSI of green space show a downward trend, the landscape of green space starts to become orderly, the fragmentation is reduced, and the green space network system is gradually formed. The landscape shape index (LPI) shows an increasing trend, indicating that the patch area of green space with dominant effect increases all the time (Perdomo-Valentín, 2016). Shannon diversity index (SHDI) increases slightly, indicating that the heterogeneity of urban green space decreases and presents a trend of balanced distribution, and the spatial layout of urban green space tends to be reasonable (Ebrahimian, 2017).

Table 3. Landscape pattern analysis in 2004-2022

\begin{tabular}{c|c|c|c|c}
\hline Year & $\begin{array}{c}\text { Green Space } \\
\text { NP }\end{array}$ & $\begin{array}{c}\text { Green space } \\
\text { LSI }\end{array}$ & $\begin{array}{c}\text { Green space } \\
\text { LPI }\end{array}$ & $\begin{array}{c}\text { Total } \\
\text { SHDI }\end{array}$ \\
\hline $\begin{array}{c}2004 \\
\text { actual measurement } \\
2010\end{array}$ & 598 & 23.3065 & 0.1347 & 1.03 \\
$\begin{array}{c}\text { actual measurement } \\
\text { 2016 }\end{array}$ & 674 & 34.1506 & 0.3674 & 1.10 \\
$\begin{array}{c}\text { actual measurement } \\
\text { 2022 } \\
\text { premeasurement }\end{array}$ & 802 & 46.9604 & 0.4323 & 1.08 \\
\hline
\end{tabular}

\section{Conclusions and discussion}

Based on the remote sensing image data of 2004 and 2010, the spatial distribution of urban green space in the northern area of Hexi new town of Nanjing in 2016 and 2022 was simulated and predicted by using CA-Markov model. The evolution of green space landscape pattern in the study area was analyzed by using four landscape indices. The following conclusions can be drawn:

(1) In this study, based on CA-Markov model and GIS and RS technologies, taking the spatial transformation of construction land, road, green space, water system and open land (unused land) as the research objects, the CA-Markov model was used to predict the scale and distribution of urban green space in northern region of Hexi new town of Nanjing in 2022. The predicted results in 2016 obtained by the experiment show that the simulation accuracy is up to $87.23 \%$ and the Kappa index is 0.8533 , indicating that the proposed conversion rules are feasible and the predicted model has high reliability. It also shows that the CA-Markov model can not only predict urban land use change, but also predict the future development of urban green space. The results can provide decision support for the dynamic regulation of urban green space.

(2) From 2004 to 2016, the area of green space in the study area has increased year by year. There are two main reasons for this result: first, due to the impact of urban 
planning and construction, green space was mainly transformed from the unused land of the study area, the unused land was reduced from $2.31 \mathrm{~km}^{2}$ in 2004 to $0.50 \mathrm{~km}^{2}$ in 2016 ; another reason is that along with the roadside trees grow up, the coverage area of road greening is also gradually increased. Therefore, the scale of green space in the study area increased from $1.52 \mathrm{~km}^{2}$ in 2004 to $3.97 \mathrm{~km}^{2}$ in 2016 , and the scale of green space will continue to increase gradually in the future.

(3) According to the change of the landscape index from 2004 to 2016, the green space in the study area has undergone a process from disorderly development to orderly development, and the layout of green space has also changed from plaque fragmentation to system network. Therefore, the spatial layout of urban green space system will become more and more reasonable.

(4) This study is an attempt to introduce CA-Markov model into the dynamic simulation of urban green space, hoping to provide a method for dynamic regulation of urban green space. However, this study is only based on the size and distribution of urban green space in 2004, 2010 and 2016 to dynamically simulate the changes of urban green space in the future. The impact of the adjustment of urban planning, the occurrence of major events and other policy changes on the construction of green space has not been considered, which may lead to greater errors in the prediction of urban green space. Therefore, in the further study, different scenarios can be set to formulate constraints, so as to make the simulation results more reasonable.

Acknowledgments. The authors acknowledge the National Natural Science Foundation of China (Grant: 31570703); Top-notch Academic Programs Project of Jiangsu Higher Education Institutions (No. PPZY2015A063); Advanced analysis and testing center of Nanjing Forestry University.

Conflict of interests. The authors declare no conflict of interests.

\section{REFERENCES}

[1] Al-shalabi, M., Billa, L., Pradhan, B. (2013): Modeling urban growth evolution and landuse changes using GIS based cellular automata and SLEUTH models: the case of Sana'a metropolitan city, Yemen. - Environment Earth Sciences 70(1): 425-437.

[2] Anan, H. S. (2019): Contribution to the paleontology, stratigraphy and paleobiogeography of some diagnostic Pakistanian paleogene foraminifer in the Middle East. Earth Sciences Pakistan 3(1): 23-28.

[3] Anputhes, M., Janmaat, J. A., Nicol, C. F. (2016): Modeling spatial association in pattern based land use simulation models. - Journal of Environmental Management 181: 465476.

[4] Asgari, A. (2018): Methods for breaking Chinese lantern (Physalis alkekengi L.) seed dormancy. Laboratory and greenhouse studies. - Revista de la Facultad de Agronomia de la Universidad del Zulia 35(2).

[5] Balzter, H. (2000): Markov chain model for vegetation dynamics. - Ecological Modeling 126: $139-154$.

[6] Bind, A., Goswami, L., Prakash, V. (2018): Comparative analysis of floating and submerged macrophytes for heavy metal (copper, chromium, arsenic and lead) removal: sorbent preparation, characterization, regeneration and cost estimation. - Geology, Ecology, and Landscapes 2(2): 61-72.

[7] Blumstein, M., Thompson, J. R. (2015): Land-use impacts on the quantity and configuration of ecosystem service provisioning in Massachusetts, USA. - Journal of Applied Ecology 52(8): 1009-1019. 
[8] Daniel, G. I., Henry, O. U., Ayodeji, B. B., Silas, M. Y. (2018): Land suitability analysis for the production of Cocoyam Inbenue State, Nigeria. - Earth Sciences Malaysia 2(2): 25-30.

[9] Ebrahimian, H. (2017): Water and energy productivity in sprinkler irrigation systems under using groundwater. - Revista de la Facultad de Agronomia de la Universidad del Zulia 34(4).

[10] Gautam, A., Batra, R., Singh, N. (2019): A study on use of rice husk ash in concrete. Engineering Heritage Journal 1(1): 01-04.

[11] Guan, D. J., Li, H. F., Inohae, T. (2011): Modeling urban land use change by the integration of cellular automaton and Markov model. - Ecological Modelling 222: 37613772 .

[12] Halmy, M. W. A., Gessler, P. E., Hicke, J. A. (2015): Land use/land cover change detection and prediction in the north-western coastal desert of Egypt using Markov-CA. Applied Geography 63: 101-112.

[13] Han, W. T., Guo, C. C., Zhang, L. Y. (2016): Classification method of land cover and irrigated farm land use based on UAV remote sensing in irrigation. - Transactions of the Chinese Society for Agricultural Machinery 47(11): 270-277.

[14] Hu, X. L., Xu, L., Zhang, S. (2013): Land use pattern of Dalian City, Liaoning Province of Northeast China based on CA-Markov model and multi-objective optimization. Chinese Journal of Applied Ecology 24(6): 1652-1660.

[15] Huang, Q. (2019): Application of ADAS multi-sensor vision simulation system for tree recognition in urban garden environment. - Revista de la Facultad de Agronomia de la Universidad del Zulia 36(1).

[16] Hulst, R. (1979): On the dynamics of vegetation: Markov chains as models of succession. - Vegetation 40: 3-14.

[17] Ismail, I., Husain, M. L., Satyanarayana, B., Ibrahim, S., Zakaria, R. (2019): Root density analysis and wave attenuation ability of Rhizophora species at Kemaman, Terengganu. Earth Sciences Malaysia 3(1): 18-24.

[18] Jiménez-Chavarría, M., Rodríguez-Arrieta, A., Salas-Fumero, F., Retana-Salazar, A. P. (2016): Descripción ultraestructural de la hoja de tres especies De Aráceas (Araceae) con características hidrofóbicas. - Acta Microscopica 25(2).

[19] Joseph, O. T., Adepoju, A. A., Olufemi, A. (2019): Biodiversity: overexploited but underutilized natural resource for human existence and economic development. Environment \& Ecosystem Science 3(1): 26-34.

[20] Kamusoko, C., Aniya, M., Adi, B. (2009): Rural sustain-ability under threat in Zimbabwe: Simulation of future land use/cover changes in the Bindura district based on the Markov-cellular automata model. - Applied Geography (29): 435-447.

[21] Lin, X. (2018a): Early warning of forest carbon sink market risk from the perspective of law. - Argos 35(69).

[22] Lin, X. (2018b): Performance evaluation of forest carbon sink in China based on principal component analysis. - Argos 35(69).

[23] Liu, J. S., Chen, Y. G. (2002): GIS-based cellular automata models and researches on spatial complexity of man-land relationship. - Geographical Research 21(2): 155-162.

[24] Liu, W. (2018): Mutual reference and integration of ecological documentaries and ecological feature films. - Argos 35(70).

[25] Mahmood, S., Kazmi, S. T., Ali, S. S. (2018): Comparison of drinking water bottles of different countries along with Zamzam water, Pakistan. - Earth Sciences Pakistan 2(1): 05-14.

[26] Mitsova, D., Shuster, W., Wang, X. (2011): A cellular automata model of land cover change to integrate urban growth with open space conservation. - Landscape \& Urban Planning 99(2): 141-153. 
[27] Moghadam, H. S., Helbich, M. (2013): Spatiotemporal urbanization processes in the megacity of Mumbai, India: a Markov chains-cellular automata urban growth model. Applied Geography 40: 140-149.

[28] Mooney, H. A., Duraiappah, A., Larigauderie, A. (2013): Evolution of natural and social science interactions in global change research programs. - PNAS 110(Suppl 1): 36653672.

[29] Naidu, M. T., Premavani, D., Suthari, S., Venkaiah, M. (2018): Assessment of tree diversity in tropical deciduous forests of Northcentral Eastern Ghats, India. - Geology, Ecology, and Landscapes 2(3): 216-227.

[30] Pascual-Córdova, G. (2018): Indicadores de calidad del suelo en el agroecosistema caña de azúcar (Saccharum spp.). - Revista de la Facultad de Agronomia de la Universidad del Zulia 35(1).

[31] Pastor, J., Sharp, A., Wolter, P. (2005): An application of Markov model to the dynamics of Minnesota's. - Journal of Forest Research 35: 3011-3019.

[32] Paul, D., Wagner, S., Murty, B., Balaji, N. (2016): Dynamic integration of land use changes in a hydrologic assessment of a rapidly developing Indian catchment. - Science of the Total Environment 539: 153-164.

[33] Perdomo-Valentín, O. (2016): Ecoconciencia y ecoactividad para la naturación urbana en estudiantes de postgrado en agricultura de México. - Revista de la Facultad de Agronomia de la Universidad del Zulia 33(4).

[34] Riitters, K. H., O'Neill, R. V., Hunsaker, C. T. (1995): A factor analysis of landscape pattern and structure metric. - Landscape Ecology 10(1): 23-39.

[35] Sarker, M. K. U., Majumder, A. K., Haque, M. Z., Hossain, M. S., Nayeem, A. A. (2019): Assessment of inland water quality parameters of Dhaka City, Bangladesh. Environment \& Ecosystem Science 3(1): 13-16.

[36] Wang, Y. (2019): Influencing factors of water-saving irrigation technology used by vegetable growers from the perspective of cost-benefit. - Revista de la Facultad de Agronomia de la Universidad del Zulia 36(1).

[37] Weber, C., Puissant, A. (2003): Urbanization pressure and modeling of urban growth: Example of the Tunis metropolitan area. - Remote Sensing of Environment 86(1/2): 341352.

[38] Weng, Q. H. (2002): Land use change analysis in the Zhujiang Delta of China using satellite remote sensing, GIS and stochastic modelling. - Journal of Environmental Management 64: 273-284.

[39] White, R., Engelen, G. (1993): Cellular automata and fractal urban form: A cellular modeling approach to the evolution of urban land use patterns. - Environment and Planning A 25(8): 1175-1199.

[40] Wu, W., Xu, L. P., Zhang, M. (2016): Impact of landscape metrics on grain size effect in different types of patches: a case study of Wuxi City. - Acta Ecologica Sinica 36(9): 2740-2749.

[41] Xu, D. (2018): Research on brand construction and development of agricultural products in Guizhou. - Engineering Heritage Journal 2(2): 19-24.

[42] Yanyan, D., Fuwen, D., Yue, L. (2019): Effect of sewage load on microenvironment and sludge reduction efficiency of situ biofilm sludge reduction system. - Acta Microscopica 28(2).

[43] Ye, B. Y., Bai, Z. K. (2007): Simulating land use/cover changes of Nenjiang County based on CA-Markov model. - Computer and Computing Technologies in Agriculture 58: 319-327.

[44] Yu, M. (2019): Impact of environmental regulation on green innovation practice of food enterprises: regulating effect of environmental awareness of different executives. Revista de la Facultad de Agronomia de la Universidad del Zulia 36(1). 
[45] Zhang, X. L., Qu, Y. H., Ren, Y. Y. (2014): Correlative analysis among pedodiversity, land use diversity and the other related ecological indexes. - Ecology and Environmental Sciences 23(6): 923-931.

[46] Zuo, T., He, L., Zhang, J. M. (2014): Dynamic change in coastal soil salinization based on the CA-Markov Model. - Resources Science 36(6): 1298-1305. 